\title{
Modified Impression Technique for Fabrication of a Custom Made Ocular Prosthesis
}

\section{Smita Sara Manoj ${ }^{*}$}

Department of Prosthodontics, Azeezia College of Dental Science and Research Centre, India

*Corresponding author: Smita Sara Manoj, Department of Prosthodontics, Azeezia College of Dental Science And Research Centre, Diamond Hills, Meeyyanoor, Kollam, Kerala, India, Tel: 91-9495539529; E-mail: drsmitamanoj@gmail.com

Received date: March 16, 2014, Accepted date: May 17, 2014, Published date: May 20, 2014

Copyright: (C) 2014 Manoj SS. This is an open-access article distributed under the terms of the Creative Commons Attribution License, which permits unrestricted use, distribution, and reproduction in any medium, provided the original author and source are credited.

\begin{abstract}
Making an impression of the anophthalmic socket to facilitate the design of a custom made ocular prosthesis is a common practice. Different impression techniques can be used for its fabrication. The modified impression technique described here requires minimum laboratory procedures as the preliminary impression, secondary impression and wax trial can be done as a single stage procedure.
\end{abstract}

Keywords: Ocular prosthesis; Custom made; Modified impression technique

\section{Introduction}

Eye is a vital organ in terms of vision and an important component of facial expression. Loss of an eye has a crippling effect on the psychology of a patient leading to significant physical and emotional problems. Surgical removal of an eye is inevitable in situations like irreparable trauma, malignant orbital tumors, infections, painful blind eye and sympathetic ophtalmia [1-4]. Surgical procedures adopted for the removal of an eye was classified by Peyman, Saunders and Goldberg (1987) into three general categories: enucleation, evisceration and exenteration. According to Scoll (1982) enucleation is a surgical procedure in which the globe and the attached portion of the optic nerve are excised from the orbit. Evisceration is removal of the contents of globe while leaving the sclera and extra ocular muscles intact. Exenteration is the most radical of the three procedures and involves removal of the eye, adnexa, and part of the bony orbit [4-7].

Prosthetic rehabilitation of patients following enucleation with an ocular prosthesis at the earliest is necessary to provide optimum cosmetic and functional result and thus improve their social status. An ocular prosthesis is a maxillofacial prosthesis that artificially replaces an eye missing as a result of trauma, surgery or congenital absence. The prosthesis does not replace missing eyelids or adjacent skin, mucosa or muscle. The ocular prosthesis does not provide vision. It is a thin hard acrylic shell like artificial eye that covers the entire surface of the eye restoring it to a normal appearance.

Ocular prosthesis is either custom made or readymade (stock eye) and impression technique is an important factor in the fabrication of an ocular prosthesis. The various impression techniques described in literature can be placed into one of the several broad categories.

Direct impression / external impression where low viscosity irreversible hydrocolloid is injected directly into enucleated socket with the patient instructed to stare straight ahead as the material sets [8-10]. Additional material is then applied to the external tissue and an impression is made using a rigid tray for reinforcement
Impression using a perforated stock ocular tray with a hollow stem in the middle through which a thin mix of ophthalmic irreversible hydrocolloid can be injected into the socket. Allen and Webster were the early proponents of this technique and called it the modified impression method $[11,12]$.

Impression with custom ocular tray as suggested by Miller involves the attachment of a solid suction rod to the patients existing prosthesis, conformer or wax shell and investing it in an irreversible hydrocolloid mould. A perforated acrylic custom tray with a tunnel in the centre is then fabricated through which an irreversible hydrocolloid or a light body consistence elastomeric impression material can be injected [13].

Impression with stock ocular prosthesis as a tray to carry the impression material or injecting irreversible hydrocolloid directly into the socket and reinforcing it by placing a stock eye.

Modification of the existing stock prosthesis by trimming and later modifying it with wax, irreversible hydrocolloid or by reline procedures.

This article describes a simple one step modified impression technique to reduce the chair side time.

\section{Impression Technique}

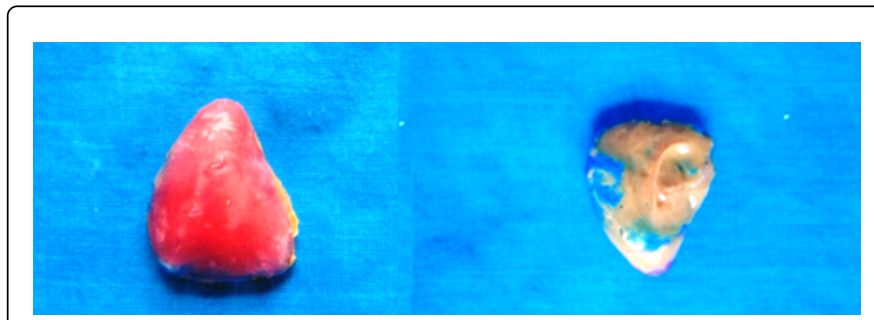

Figure 1 and 2: Putty index with the secondary impression on the intaglio surface and the wax scleral form on the opposing surface.

1. Make a preliminary impression of the socket using the putty consistency of polyvinyl siloxane impression material. Form a 
Page 2 of 2

small ball of the putty material and place it into the socket and ask the patient to do various eye movements. The putty index so formed will serve as a matrix for the secondary impression material on the intaglio surface and for the wax pattern of the sclera on the outer aspect (Figure 1 and 2).

2. Adapt modelling wax to the external surface of the putty index using mechanical retention in the form of grooves inscribed on the putty surface.

3. Do waxes try in of the sclera.

4. With the wax sclera in position, make a secondary impression of the tissue surface using light body elastomeric impression material and asking the patient to be seated erect staring at a distant spot and instructing to hold his gaze in a straight forward position with the eyes open while the impression is being made.

5. Once the impression material sets, adjust the wax pattern further while the patient is asked to do various eyeball movements (Figure 3).

6. Invest the pattern so obtained and polymerise using heat activated resin to obtain an acrylic shell.

7. Adjust the acrylic shell after placing it in the patients' socket.

8. Fabricate the final prosthesis using any of the conventional techniques (Figure 4 and 5).

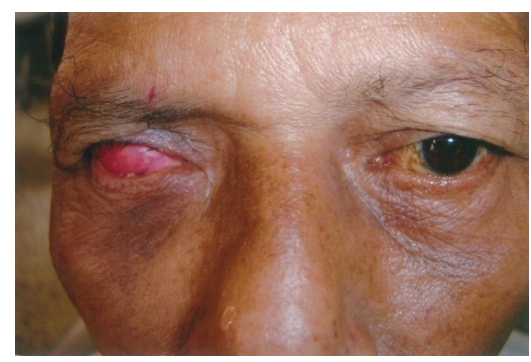

Figure 3: Adjustment of the wax pattern for determination of the final contour

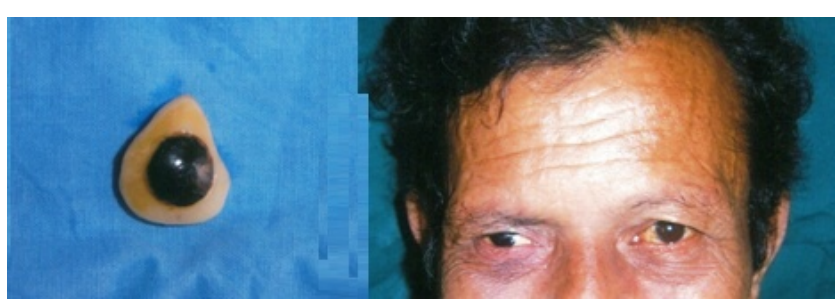

Figure 4 and 5: Final prosthesis

\section{Discussion}

An ocular prosthesis fabricated from an accurate impression of the underlying mobile tissues will offer better patient comfort and compliance, prosthesis accuracy and esthetics. Numerous ocular impression techniques have been described in literature, All these techniques requires multiple clinical and laboratory procedures like obtaining a preliminary impression, fabrication of a custom tray, pouring of two piece stone models.

The one step modified impression technique described here does not require the fabrication of a custom tray nor the pouring of two piece stone models. Impression making and wax try in can be conducted as a single stage procedure, thus reducing the number of patient's visit to the clinic. Besides in this technique, the socket can be recorded in full detail using the dimensionally stable light body consistency of polyvinyl siloxane impression material. This technique can be applied only in case of ocular defects with adequate depth between the fornices. It cannot be used in large orbital defects.

\section{Conclusion}

Impression technique is a prime requirement for the fabrication of an artificial eye. The technique described here is very simple without the need for any tedious laboratory procedures and reduced number of patient's clinical visit.

\section{References}

1. Kale E, Mese A, Izgi AD (2008) A technique for fabrication of an interim ocular prosthesis. J Prosthodont 17: 654-661.

2. Jebreil K (1980) Acceptability of orbital prosthesis. J Prosthet Dent 43: 82-85.

3. Supriya M, Ghadiali B (2008) Prosthetic rehabilitation of a patient with an orbital defect using a simplified approach. J Indian Prosthodont Soc 116-118.

4. Gupta RK, Padmanabhan TV (2012) Prosthetic rehabilitation of a post evisceration patient with custom made ocular prosthesis: a case report. J Indian Prosthodont Soc 12: 108-112.

5. Bindhoo YA, Aruna U (2011) Prosthetic rehabilitation of an orbital defect: A case report. J Indian Prosthodont Soc 11: 258-264.

6. Perman KI, Baylis HI (1998) Evisceration, enucleation and exenteration. Otolaryngol Clin North Am 21: 171-182.

7. Mishra SK, Ramesh C (2009) Reproduction of custom made eye prosthesis maneuver: A case report. J Dent Oral Hyg 1: 59-63.

8. Appanna PA, Porwal A, Verma N (2009) Impression techniques for ocular prosthesis- A clinical review. International journal of dental clinics 1:27-31.

9. Bartlett SO, Moore DJ (1973) Ocular prosthesis: A physiologic system. J Prosthet Dent 29: 450-459.

10. Brown KE (1970) Fabrication of an ocular prosthesis. J Prosthet Dent 24: 225-235.

11. Allen L, Webster HE (1969) Modified impression method of artificial eye fitting. Am J Ophthalmol 67: 189-218.

12. Allen L, Bulgarelli D (1988) Obtaining and understanding the alginate impressions. J Am Soc Ocularists 19: 4-13.

13. Miller B (1996) Custom ocular impression trays. J Facial Somato Prosthet 2: 109-113. 